\title{
PRÁTICAS DE LETRAMENTO E COMPREENSÃO LEITORA NA ESCOLA: A MULTIMODALIDADE EM PERSPECTIVA
}

\author{
BRIANE SCHMITT \\ UNIVERSIDADE DE PASSO FUNDO \\ PASSO FUNDO, RIO GRANDE DO SUL, BRASIL \\ BRIANELETRAS@GMAIL.COM \\ ERNANI CESAR FREITAS \\ UNIVERSIDADE DE PASSO FUNDO \\ PASSO FUNDO, RIO GRANDE DO SUL, BRASIL \\ ECESAR@UPF.BR \\ IVERTON GESSÉ RIBEIRO GONÇALVES \\ UNIVERSIDADE DE PASSO FUNDO \\ PASSO FUNDO, RIO GRANDE DO SUL, BRASIL \\ HYWERTTHOM@HOTMAIL.COM
}

HTTP://DX.DOI.ORG/10.5902/2316882X25011 


\section{PRÁTICAS DE LETRAMENTO E COMPREENSÃO LEITORA NA ESCO-}

\section{LA: A MULTIMODALIDADE EM PERSPECTIVA}

Resumo: Este estudo propõe-se a compreender e analisar textos multimodais que permeiam as interações comunicativas em sociedade, focando especialmente na maneira como a instituição escolar os maneja e os apresenta aos alunos. O principal objetivo da pesquisa é entender de que maneira o processo de compreensão textual multimodal é realizado pelos estudantes, para que desse estudo possamos pensar formas mais eficazes de trabalhar a multimodalidade.

Palavras-chave: Gêneros do Discurso; Multimodalidade; Compreensão leitora; Letramento.

\section{PRACTICAS DE LETRAMENTO Y COMPRENSIÓN LECTORA EN LA ESCUELA: LA MULTIMODALIDAD EN PERSPECTIVA}

Resumen: Esto estudio tiene como objetivo comprender y analizar textos multimodales que involucran las interacciones comunicativas en la sociedad, centrándose sobre todo en cómo la escuela los administra y presenta a los estudiantes. El objetivo principal de la investigación es entender cómo los estudiantes realizan el proceso de comprensión de textos multimodales, por lo que este estudio puede proponer formas más eficientes de trabajar multimodalidad en clase.

Palabras clave: Géneros de Discurso; Multimodalidad; Comprensión lectora; Letramento.

PRACTICES OF LITERACY AND UNDERSTANDING READER AT SCHOOL: THE MULTIMODALITY IN PERSPECTIVE

Abstract: This research wants to understand and analyze the multimodal texts that permeate the communicative interactions in society, focusing especially on how the educational institution manages and introduces it to the students. The main objective of the research is to understand how the multimodal text comprehension process is accomplished by the students, so this study can enable us to create more effective ways of working multimodality.

Key-words: discourses genres, multimodality, reader comprehension, literacy. 


\section{INTRODUÇÃO}

Os desafios que permeiam as práticas educacionais na escola contemporânea, a formação de estudantes leitores capazes de significar não só o mundo a sua volta, mas também a vasta gama de interações comunicativas pelas quais a sociedade significa e é significada, configura-se como uma problemática passível de discussões interessantes e, antes de mais nada, necessárias. Esse estudante do mundo contemporâneo do qual falamos é um indivíduo que vive permanentemente bombardeado de informações que circulam e se movimentam em um tecido, uma rede de permutas comunicativas complexas. É essa complexidade, esse movimento, essa fluidez de sentidos e significações que necessita de mediação por parte de educadores e professores, para que tais informações de fato possam fazer parte do processo educativo, de maneira que o aprendizado venha ser construído e solidificado pelo aprendiz. Portanto, o problema de pesquisa ao qual este trabalho procura responder se define a partir do seguinte questionamento: de que maneira os sujeitos leitores do mundo contemporâneo constroem significados a partir de textos multimodais?

Para que a mediação pelo professor possa ser realizada, se faz necessário, primordialmente, o entendimento do processo de leitura e compreensão de textos multimodais realizado pelo sujeito leitor. Dessa forma, este estudo tem como principal objetivo analisar a maneira pela qual os estudantes da escola contemporânea realizam os diferentes movimentos de leitura necessários ao discernimento dos mais variados textos, pontuando a presença da multimodalidade nas experiências comunicativas com as quais esses alunos entram em contato. Para isso, alguns pressupostos teóricos são necessários na busca de um maior entendimento sobre essa experiência multimodal que os estudantes e a sociedade vivenciam no cotidiano. Desse modo, esta pesquisa considera as noções sobre gêneros do discurso defendidas por Mikhail Bakthin (1997), Fiorin (2008) e Marcuschi (2008), além das contribuições teóricas de Rojo (2013) e Magda Soares (2004) sobre multimodalidade. O corpus desta pesquisa define-se a partir da prática leitora multimodal aplicada em sala de aula, que teve como assunto norteador o preconceito, a discriminação e a imposição de padrões pela sociedade. A pesquisa tem caráter exploratório e bibliográfico, configurando-se como pesquisa-ação, já que é voltada para uma intervenção na realidade que merece investigação. A abordagem do estudo é qualita- 
tiva, uma vez que busca a compreensão dos movimentos acionados para uma leitura multimodal a partir da análise dos processos ocorridos em sala de aula.

Primeiramente, será apresentada uma delimitação teórica a fim de explanar sobre os principais conceitos e noções que darão suporte à análise aqui proposta. Posterior a isso, com base nos resultados e análises obtidos da prática leitora aplicada, o corpus dessa pesquisa será analisado a fim de que possamos desvendar os processos de leitura envolvidos na compreensão de textos multimodais, analisando, de forma concomitante, possíveis práticas de leitura multimodal a serem adotadas, na busca de atividades leitoras mais eficientes e significativas para os sujeitos envolvidos nesse processo, sejam eles educadores ou alunos.

\section{AS DIVERSAS FORMAS DE DIZER}

A atividade humana em sociedade é permeada por necessidades comunicativas de todas as origens, já que é através da comunicação que significamos o mundo e somos por ela significados. Dessa forma, cada situação comunicativa requer uma diferente forma de dizer por parte do falante, pois nessas diferentes situações também se configuram diferentes objetivos. Sendo assim, "a vontade discursiva do falante se realiza antes de tudo na escolha de um certo gênero do discurso" (BAKHTIN, 2003, p. 282, grifo do autor).

Os gêneros do discurso são tipos de enunciados relativamente estáveis que circulam em todas as esferas comunicativas da sociedade. $O$ interessante é que, na grande maioria das vezes, os sujeitos falantes não percebem que, toda vez que se comunicam, o fazem escolhendo determinado gênero ou gêneros discursivos, de acordo com seu objetivo de significação. Daí vem a importância de trazermos à tona os diferentes gêneros do discurso que utilizamos, procurando entender de que maneira eles se apresentam a nós. Essa relativização referente aos tipos de enunciados que constituem os gêneros discursivos diz respeito ao fato de que a sociedade está em constante processo de mudança, e uma vez que os gêneros do discurso configuram-se como um reflexo das necessidades comunicativas, eles, por sua vez, precisam acompanhar essa dinamicidade que permeia nossas interações. Dessa maneira, não podemos caracterizar os gêneros como formas fixas, mas sim como formas que se adaptam e se

Rev.Cad.Comun. Santa Maria, v.21, n.3, art 1, p.16 de 31, set/dez.2017 
ajustam àquilo que os sujeitos falantes necessitam para significar e construir sentido num determinado tempo e espaço.

Os gêneros discursivos são uma espécie de reflexo das interações sociais. Um interfere diretamente no outro, tornando o estudo dos gêneros discursivos um tanto quanto interessante. "O gênero estabelece, pois, uma interconexão da linguagem com a vida social. A linguagem penetra na vida por meio dos enunciados concretos e, ao mesmo tempo, pelos enunciados a vida se introduz na linguagem" (FIORIN, 2008, p. 61). Estudando um pouco a perspectiva sobre os gêneros discursivos sob a visão de Marcuschi (2008), percebemos que a escola contemporânea já se deu conta da necessidade de trabalhar os diferentes gêneros do discurso existentes, porém está fazendo isso de forma lenta e com dificuldades. Segundo o autor, são vários os livros didáticos de língua portuguesa que apresentam uma relativa variedade de gêneros, mas esses se repetem continuamente, como se fossem os únicos que devessem ser estudados.

Tendo em vista que o estudo dos diferentes gêneros discursivos é indispensável para a formação de sujeitos leitores, partimos agora para a discussão sobre letramento e sua relação com a multimodalidade, aspectos que constituem um grande desafio aos professores não só de língua, mas a todos os educadores que precisam mediar a relação entre sociedade, ensino e estudante.

\section{RESSIGNIFICANDO O SABER LER}

Para os educadores e alunos dos primeiros níveis escolares, a alfabetização caracteriza-se como ponto muito relevante do processo de aprendizagem. Ao aprender a ler, novas possibilidades vão se formando no horizonte tanto do aluno, que se depara com um novo mundo de construção de significados, quanto do professor, que certamente enxerga no processo de alfabetização a chave do sucesso para o desenvolvimento intelectual do estudante. Ao aprender a ler, a criança vai se tornando capaz de compreender melhor o mundo a sua volta, e esse é um processo intermitente já que "a aprendizagem da língua materna, quer escrita, quer oral, é um processo permanente, nunca interrompido" (SOARES, 2004, p. 15). Dessa forma, é necessário que a escola permaneça em um contínuo processo de ensino e aprendizagem de leitura, já que a sociedade e suas trocas comunicativas estão em constante mudança, e essas alterações

Rev.Cad.Comun. Santa Maria, v.21, n.3, art 1, p.17 de 31, set/dez.2017 
refletem diretamente nos textos que circulam nos mais diversos meios e contextos sociais.

Mas de que leitura estamos falando? Magda Soares (2004) explica claramente que há sim uma diferença de significados entre os conceitos de alfabetização e letramento, sendo que "etimologicamente, o termo alfabetização não ultrapassa o significado de "levar à aquisição do alfabeto"” (SOARES, 2004, p. 15). Sendo assim, o que nos interessa neste estudo é o aprendizado de leitura que vai além da decifração de códigos, que é permeado por diversas significações que são resultados dos processos sociais nos quais este ou aquele texto está inserido. Nosso objeto de estudo aqui se trata do letramento, mais especificamente do letramento multimodal, ou multiletramento.

As práticas de letramento na contemporaneidade são extremamente desafiadoras para os educadores, uma vez que a instituição escola vem passando por um processo muito lento de readaptação à realidade social que hoje nos é apresentada, e que requer do aluno a capacidade de ler os mais diferentes textos nos mais diversos suportes. Portanto, esse multiletramento diz respeito

(...) por um lado, à multiplicidade de linguagens, semioses e mídias envolvidas na criação de significação para os textos multimodais contemporâneos e, por outro, à pluralidade e à diversidade cultural trazida pelos autores/leitores contemporâneos a essa criação de significação. (ROJO, 2013, p. 14).

Assim, esse letramento multimodal se torna uma ferramenta necessária para o estudante de fato se tornar um sujeito capaz de realizar as interpretações dos fatos e acontecimentos e ser atuante perante esses. Mas como começar a desenvolver essa leitura atenciosa e crítica que um letramento multimodal exige? Já foi constatado que a escola tradicional 'muitas vezes ignora formas sociais orais e visuais de extrema relevância para a construção de significados ímpares, promovendo apenas o apren-

1 Escola tradicional, aqui, refere-se ao modo como as práticas de ensino e aprendizagem normalmente são desenvolvidas em sala de aula, muitas vezes não apresentando textos autênticos, no caso de ensino de língua materna ou língua adicional, e sem explorar os níveis de análise textuais que têm a ver com o discurso, as condições de produção, o contexto.

Rev.Cad.Comun. Santa Maria, v.21, n.3, art 1, p.18 de 31, set/dez.2017 
dizado de leitura escrita e dando foco ao código linguístico, em sua forma e estrutura no texto.

Levando isto em consideração, a proposta de prática leitora, que delimita-se como o corpus deste trabalho, foi construída a partir do pressuposto de que todas as formas de significação são importantes para a construção da habilidade de leitura, que dessa maneira se torna multimodal. Assim, os textos que compõem a prática leitora aplicada em sala de aula vão desde campanhas publicitárias, nas quais imagens suscitam diversos significados, até vídeo clipes, que abrangem um mundo de significados sonoros, imagéticos e também verbais, trabalhando com diferentes gêneros discursivos. O tema que delimitou a seleção de textos, para fins da pesquisa-ação desenvolvida, foi o preconceito e os padrões e estereótipos que permeiam nossa sociedade. Tal escolha foi muito relevante e assertiva, pois não só suscitou os mais diferentes debates em sala de aula como reforçou a ideia de que aulas de língua, leitura e interpretação fazem, sim, parte da vida real dos estudantes, e que os aprendizados realizados dentro da sala de aula são diferenciais para o sujeito atuante na sociedade.

Após a aplicação das oficinas em sala de aula, foi possível obter muitas considerações em torno dos aspectos que dizem respeito ao ensino de texto multimodais. As análises e considerações quanto às atividades propostas seguem no próximo item deste artigo.

\section{O DESAFIO DO LETRAMENTO MULTIMODAL NA ESCOLA}

Para que este estudo sobre letramento multimodal pudesse ser realizado, foi necessária a implementação de uma prática leitora com oficinas diretamente aplicadas em sala de aula, com alunos do segundo ano do ensino médio da rede pública estadual da cidade de Passo Fundo. Levando em consideração que a sala de aula é lugar de construção de saberes relacionados principalmente à vida em sociedade, o assunto que permeou a escolha de textos da prática girou em torno dos preconceitos e estereótipos que fazem parte das trocas sociais e que, por esse motivo, estão diretamente ligados aos fatos linguísticos que nesta análise nos propomos a apresentar.

A prática leitora foi desenvolvida em oito períodos curriculares ( 4 oficinas), sendo que a cada dois períodos um novo texto era apresentado aos alunos, no intuito de analisar a maior quantidade possível de significações

Rev.Cad.Comun. Santa Maria, v.21, n.3, art 1, p.19 de 31, set/dez.2017 
das materialidades linguísticas selecionadas. O corpus desta pesquisa, a princípio, seria obtido apenas dos textos pré-selecionados para as oficinas e também das impressões de como os estudantes entraram em contato com a multimodalidade, seus comentários orais e outros aspectos percebidos durante as atividades em sala de aula. Contudo, ao final de cada oficina, os estudantes eram levados a produzir parágrafos e textos respondendo perguntas referentes a compreensão multimodal. Esses registros, portanto, tornaram-se muito importantes na tentativa de responder ao problema de pesquisa deste trabalho. Sendo assim, o corpus é composto pelos textos multimodais e pelos registros dos estudantes, uma vez que esta caracteriza-se como uma pesquisa-ação e, portanto, torna-se imprescindível a análise do resultado desta ação.

A primeira oficina realizada foi a que mais gerou discussões e na qual pudemos observar o ato de confronto entre o aluno e o texto multimodal. Falamos em confronto, pois a primeira sensação percebida entre os alunos foi exatamente de espanto e surpresa. Esse impasse observado caracteriza e coloca à prova o que já se percebe há muito tempo: a escola permanece com resquícios do ensino que chamamos de tradicional. No caso do ensino de língua portuguesa, o texto escrito permanece sob um estigma de ser o mais adequado, o correto, o que deve ser estudado, ficando as tantas outras formas de significação e de construção de saberes em segundo plano, na maioria das vezes nem mesmo sendo apresentadas. Já esperando esse choque, que de fato ocorreu, em relação aos textos escolhidos para a realização das oficinas, o primeiro texto analisado foi de uma campanha publicitária da grife de moda masculina Reserva, lançada no início do inverno de 2015 e que tinha como ideia principal o enunciado "Faça como os animais, não julgue". Seguem os textos publicitários que foram analisados em sala de aula, conforme Figura 1.
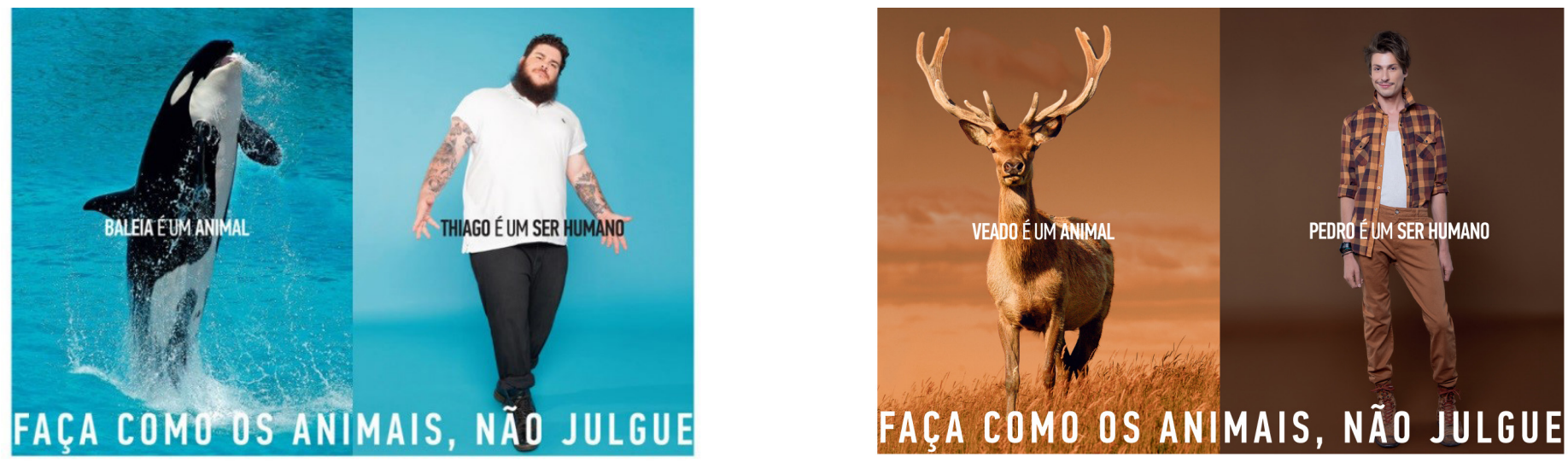

Rev.Cad.Comun. Santa Maria, v.21, n.3, art 1, p.20 de 31, set/dez.2017 

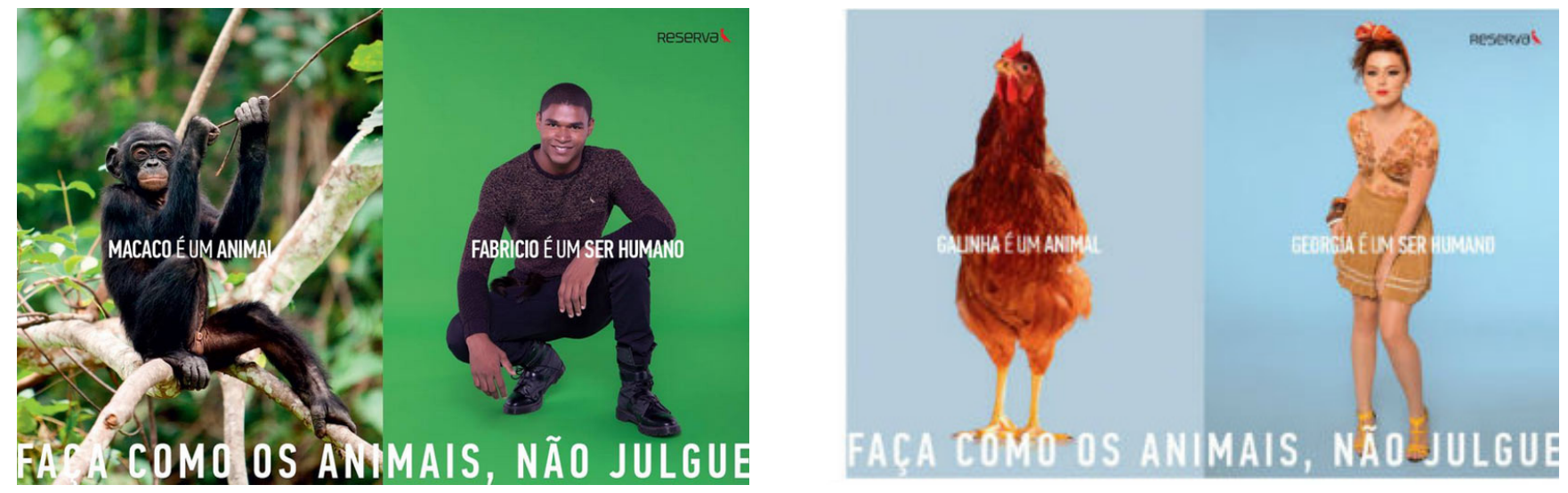

Figura 1 - Campanha publicitária

Fonte: Blog A Gambiarra (2015)

Como posto anteriormente, os gêneros discursivos são como reflexos das relações sociais e, em especial, o gênero publicitário tende a explicitar ainda mais alguns processos sociais frequentes, já que seu maior objetivo é convencer seu coenunciador daquilo que afirma. Trabalhar com o gênero publicitário nesta pesquisa, portanto, nos possibilitou avaliar como as interpretações e as construções de sentido se dão em torno dos assuntos de que trata a campanha publicitária: preconceito, discriminação e imposição de padrões sociais. Ao apresentar as imagens da campanha publicitária, foi possível notar esse estranhamento que materialidades semióticas diferentes do texto escrito tradicional podem gerar nos alunos. Apesar deste primeiro estranhamento, precisamos insistir no desenvolvimento da cultura do letramento multimodal, uma vez que "já não basta mais a leitura do texto verbal escrito - é preciso colocá-lo em relação com um conjunto de signos de outras modalidades de linguagem (imagem estática, imagem em movimento, som, fala)" (ROJO, 2013, p. 20).

Essa campanha publicitária questiona diversos preconceitos que permeiam nossas relações sociais e que foram prontamente identificados pelos estudantes. Esse reconhecimento de uma prática que faz parte da vida do estudante e que é identificado por ele é essencial para que o professor consiga alcançar os objetivos aos quais se propôs na relação ensino/aprendizagem. Ao dar sequência à atividade, um pequeno debate oral foi realizado com os estudantes, a partir das questões norteadoras que seguem: 
- O que chama mais atenção nas imagens?

- Quais sentidos são construídos a partir da forma como as imagens dos animais e dos seres humanos aparecem relacionadas?

- Existe alguma relação entre as cores de fundo, as roupas e os animais? Qual?

Tais perguntas foram produzidas procurando seguir uma sequência lógica, na tentativa que começar a desenvolver a habilidade da leitura multimodal nos estudantes. A primeira pergunta se refere a uma leitura mais geral das imagens, daquilo que eles perceberam ao entrar em contato com a propaganda publicitária. Nesse primeiro momento foi possível observar que os estudantes levaram em consideração apenas as imagens, não relacionando-as com a materialidade linguística presente na campanha. A partir da segunda questão, uma nova concepção de texto começou a ser criada pelos estudantes. Ao perguntar que sentidos eram construídos a partir das imagens vários questionamentos começaram a surgir.

Num primeiro momento, os estudantes tiveram dificuldades em responder a essa pergunta, já que não é costume da escola tradicional lidar com textos imagéticos. Neste momento foi necessária uma intervenção mais direta para que os estudantes pudessem realizar a leitura requerida. Chamando a atenção para o modo como as figuras dos seres humanos e dos animais estavam relacionadas, as cores destas e as posições das imagens os estudantes conseguiram depreender os significados esperados: a campanha publicitária coloca o ser humano e o animal em um nível de igualdade. É importante ressaltar que os estudantes chegaram a essa conclusão levando em consideração apenas a leitura das imagens. Como etapa posterior, propusemos aos estudantes que prestassem atenção e procurassem analisar os sentidos construídos apenas com base nas materialidades linguísticas presentes na campanha. Antes desta análise, retomamos qual seria o objetivo principal da campanha. Todos os estudantes concordaram que o objetivo tratava-se de uma crítica e de uma forma de tentar diminuir o preconceito que existe na sociedade. Portanto, levando em consideração o intuito de acabar com o preconceito da campanha e apenas a materialidade linguística presentes nos textos, propusemos aos estudantes que respondessem de forma escrita a seguinte pergunta: 
- Caso os dois primeiros enunciados de cada imagem (por exemplo: baleia é um animal/Thiago é um ser humano) fossem transcritos em um único enunciado, de que forma ele se estruturaria?

Tal questionamento gerou respostas muito parecidas em sua estrutura. Segue abaixo recortes de resposta de três estudantes que participaram da prática leitora:

Enunciado 1: "Baleia é um animal, porém Thiago é um ser humano" Enunciado 2: "Galinha é um animal, mas Geórgia é um ser humano" Enunciado 3: "Baleia é um animal, diferente de Thiago que é um ser humano"

Neste momento da prática leitora iniciou-se um debate muito interessante, já que a campanha publicitária não parecia estar coerente, uma vez que, ao analisarem apenas as imagens, os estudantes haviam chegado à conclusão de que a campanha publicitária procurava estabelecer um estado de igualdade entre o ser humano e os animais. Ao analisarem e responderem a esse último questionamento, a conclusão foi outra: pela materialidade linguística foi possível observar que, ao contrário do que havia sido constatado antes, a campanha publicitária, neste recorte, reforçava a ideia de que seres humanos e animais não podem ser colocados em nível de igualdade. Tal contradição gerou uma discussão muito importante para a questão da multimodalidade que aqui investigamos. Os estudantes foram confrontados e instigados a pensar sobre qual significado deveria ser levado em consideração: aquele advindo da análise apenas das imagens, o que partia da análise da materialidade linguística ou, ainda, as duas semióticas trabalhando em conjunto na construção do significado.

É neste instante que se desenha o desafio do letramento multimodal na escola. De que forma explicar aos alunos que campanhas publicitárias como esta que foi trabalhada se tratam de textos multimodais, ou seja, que se utilizam de diversos modos para significar e serem significados e que, portanto, devem ser levados em consideração todos esses diferentes modos de significar o texto? De que maneira fazer esse aluno da escola tradicional entender que tudo aquilo que faz parte de um texto é essencial para a construção de significado deste?

Ao utilizarmos um texto multimodal advindo de uma campanha publicitária cujo significado foi construído com algumas falhas devido à contra-

Rev.Cad.Comun. Santa Maria, v.21, n.3, art 1, p.23 de 31, set/dez.2017 
dição presente nos suportes verbais e não verbais do texto, foi possível constatar que os alunos perceberam, de fato, que todas as formas utilizadas para construir o significado de determinado texto devem ser levados em consideração no momento da leitura, pois todos se complementam ou deveriam se complementar (como é o caso do recorte de corpus aqui analisado). Talvez essa seja uma sugestão interessante para ser colocada em prática ao trabalhar textos multimodais em sala de aula: mostrar aos alunos não exemplos de textos multimodais que são bem sucedidos, mas justamente aqueles que, como esta campanha publicitária, se perdem na questão da concomitância de sentidos que um texto multimodal deve ter em relação às suas diferentes formas de expressão. Vale ressaltar que este texto também suscita uma questão que está cristalizada no imaginário social, isto é, há uma crítica ao comportamento social na polissemia das palavras. Ao se utilizar de estereótipos como "baleia", "veado" "macaco", se constrói aí uma polissemia que a campanha tenta desconstruir mas acaba falhando. No decorrer destas oficinas, algumas das atividades propostas foram de grande valia, já que nos permitiram a análise do modo como esses estudantes entram em contato com textos multimodais e as maneiras como reagem a eles.

A última oficina proposta nesta sequência de atividades em sala de aula foi de extrema importância, pois aí pudemos, de fato, perceber como a multimodalidade está presente, na grande maioria das vezes, no cotidiano deste estudante, que precisa despertar para este mundo multimodal que o rodeia e que tantas vezes é deixado de lado pela escola tradicional. Na quarta oficina desta prática leitora foi apresentado aos alunos o videoclipe da música Pretty Hurts, interpretado pela cantora de música pop Beyoncé. A escolha desta música foi de essencial importância, já que sua letra trata-se de um texto riquíssimo de significados e seu vídeo clipe é, certamente, fonte de várias discussões quanto ao modo como é apresentado. Segue um pequeno trecho da letra, bem como imagens do vídeo clipe analisadas pelos estudantes, como consta na Figura 2.

\section{Enunciado 4:}

Pretty hurts

We shine the light on whatever's worse

Perfection is the disease of a nation

Pretty hurts

We shine the light on whatever's worse

Rev.Cad.Comun. Santa Maria, v.21, n.3, art 1, p.24 de 31, maio/ago.2017 
Tryna fix something

But you can't fix what you can't see

It's the soul that needs the surgery
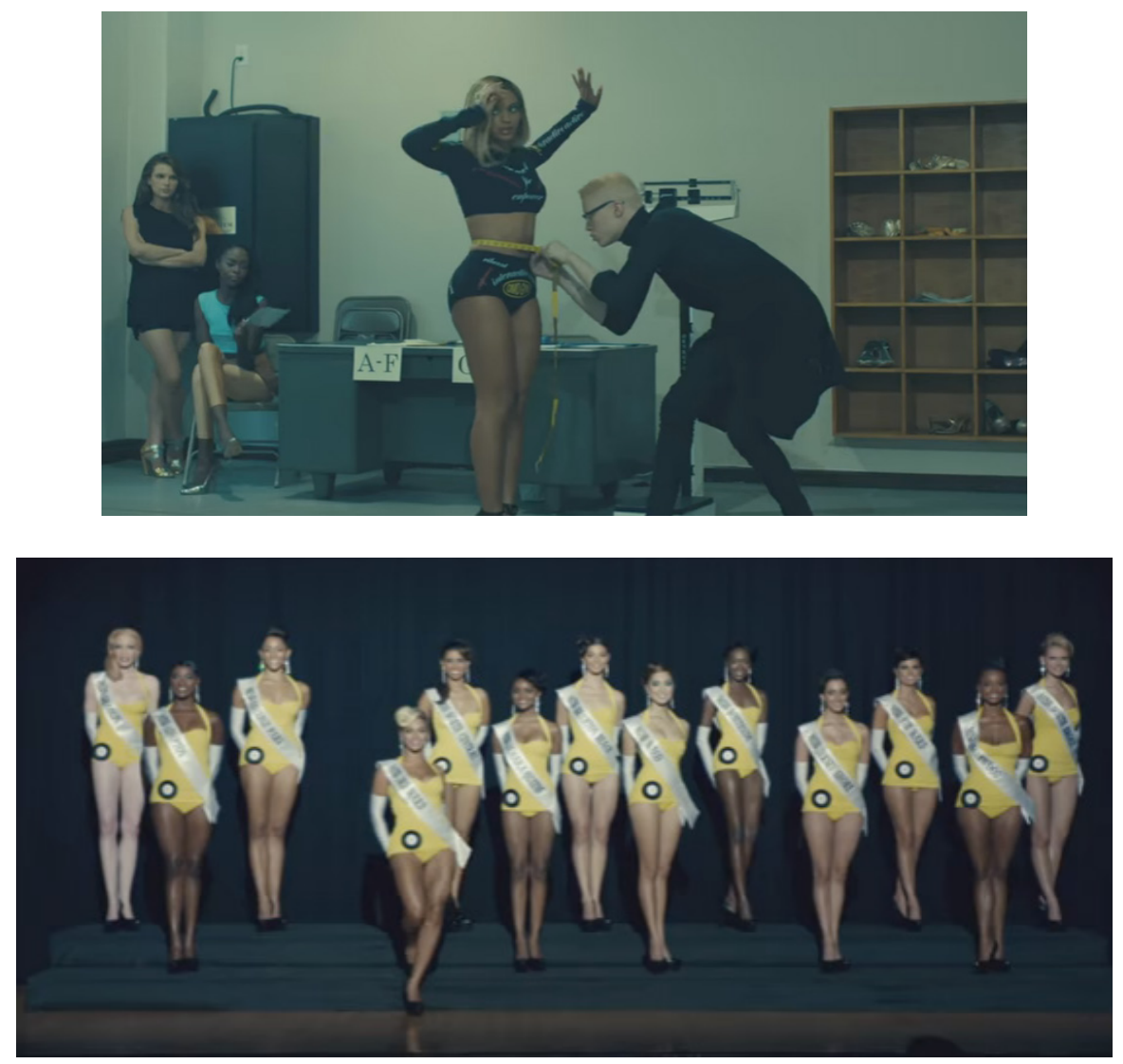

Figura 2 - Videoclipe Fonte: YouTube 2014

Este gênero do discurso proposto aqui para análise levou os estudantes a pensarem sobre os textos que fazem parte das suas vidas. A escola tradicional vem implantando um sistema no qual apenas a variedade padrão da língua é válida, assim como apenas a modalidade do texto verbal é levada em consideração. É preciso desmitificar este pensamento, já que "todas as esferas de atividade humana se caracterizam como esferas de comunicação verbal, o que lhes confere sua qualidade propriamente humana" (ROJO, 2015, p. 64). Num primeiro momento, os alunos assistiram ao videoclipe sem pausa. No final desta primeira parte os estudantes já foram capazes de assimilar o sentido geral do texto, e um pequeno debate foi realizado, levando em consideração o tema do preconceito e dos padrões de beleza impostos pela sociedade que permeou a escolha de todos 
os textos trabalhados nesta prática leitora.

Após o primeiro contato com o texto, iniciamos uma análise mais detaIhada. Ao reproduzir o videoclipe novamente, pausando-o em momentos nos quais a questão da leitura imagética era requerida, os alunos puderam perceber e comentar aspectos que antes passaram despercebidos, tais como as expressões faciais das pessoas que apareciam nas imagens, a cor de suas roupas, suas posições corporais, o jogo de luzes, o jogo de sons, dentre outros. No decorrer da discussão desses aspectos sempre houve o momento em que analisamos a materialidade linguística que deveria estar intrinsicamente conectada a esses referentes não verbais.

É muito importante ressaltar que já no início desta análise os estudantes conseguiram perceber que, diferentemente da propaganda publicitária trabalhada na primeira oficina, este texto multimodal não se perdia em contradições, e toda materialidade não verbal que eles conseguiram destacar no videoclipe condizia com o linguístico, ou seja não havia contradição. Para finalizar esta prática leitora, foi proposta uma produção textual de 30 a 35 linhas na qual os estudantes deveriam responder às seguintes questões norteadoras:

- O que é multimodalidade?

- Como as imagens do videoclipe ajudam a construir os significados do vídeo?

- Você acha importante saber ler de diferentes modos?

A partir dessas produções textuais, destacamos os textos de seis estudantes em que conseguimos perceber questões muito interessantes de serem debatidas neste estudo da leitura e do letramento multimodal o qual nos propomos a realizar. Segue o primeiro recorte a ser analisado.

Enunciado 5: "Multimodalidade é as diferentes formas de leitura, leitura não é apenas só ler um texto ou um livro etc. Há diferentes formas de ler você pode ter uma imagem, uma história em quadrinhos e até tem multimodalidade em clipes musicais através das imagens que complementam a letra da música".

Neste trecho escrito por um dos estudantes, é possível observar um aspecto da multimodalidade que, de certa forma, já estávamos cientes: a escola tradicional deixa a desejar nessas questões de letramento multimodal, e este aluno sente-se, de certa forma, confrontado por algo que faz

Rev.Cad.Comun. Santa Maria, v.21, n.2, art 1, p.26 de 31, maio/ago.2017 
parte do seu cotidiano, mas que não lhe é dada a oportunidade nem as ferramentas necessárias para que possa usufruir deste tipo de leitura. A expressão em destaque no Enunciado 5 prova isso. $O$ estudante demonstra espanto quanto ao fato de a multimodalidade, certamente poucas vezes ou nunca comentada em sala de aula, fazer parte tão diretamente da sua vida cotidiana. No enunciado que segue, o estudante, ao relatar como a multimodalidade faz parte do nosso dia a dia, dando o exemplo de placas de trânsito e propagandas, se dá conta de um aspecto importante sobre essas utilizações multimodais dizendo que:

Enunciado 6: "[...] elas são bem usadas, mais não são valorizadas"

E aqui nos é apresentada uma verdade maior: na primeira oportunidade que este estudante teve de entrar em contato com um texto multimodal e, mais importante que tudo, pensar sobre o texto, em como é apresentado e com que frequência em nosso cotidiano nos deparamos com textos multimodais, esse aluno já consegue perceber que o letramento que se apresenta de diversos modos, proposto nas oficinais desta prática leitora, é uma atividade não valorizada, principalmente pela escola tradicional. Nossas suspeitas se concretizam: há uma lacuna no letramento proposto pela escola. Este é o motivo principal para que estudos, assim como este que foi realizado, seja debatido e posto em prática constantemente.

É preciso reverter a situação, já que saber ler é saber posicionar-se diante da sociedade. É interessante saber que, ao finalizar nossa prática leitora em sala de aula, a percepção de algo muito importante pôde ser ativada nos estudantes, como é possível perceber nos recortes seguintes:

Enunciado 7: "Sempre é bom saber interpretar uma imagem, são muito úteis no dia a dia das pessoas"

Enunciado 8: "Nossa vida é constituída de ações multimodais"

Sim, nossa vida é constituída de ações multimodais, uma vez que levamos em consideração que "[...] a língua passa a integrar a vida através de enunciados concretos (que a realizam); é igualmente através de enunciados concretos que a vida entra na língua" (BAKHTIN, 2003, p. 265). Portanto, só podemos nos conceber como participantes ativos da sociedade no momento em que utilizamos essa ferramenta que nos diferencia de qualquer outro animal vivo na terra: a linguagem. E se utilizamos a linguagem, devemos ser capazes de fazer isso das mais diversas formas. Ao privar

Rev.Cad.Comun. Santa Maria, v.21, n.2, art 1, p.27 de 31, maio/ago.2017 
nossos estudantes da exploração dos tantos significados que permeiam nossas trocas sociais, não estamos apenas impedindo-os de conhecer e utilizar a linguagem nos vários aspectos possíveis, mas criamos também uma barreira na vida social deste estudante, que sem as ferramentas próprias se vê incapacitado de se posicionar criticamente em seus momentos de interação.

Nossa vida é multimodal. E os educadores muitas vezes caem na armadilha de subestimar os estudantes, acreditando que estes não são capazes de perceber essas minúcias que permeiam o aprendizado. Os estudantes são perfeitamente capazes de perceber os processos que dizem respeito a sua aprendizagem, tanto no aspecto escolar quanto social. $O$ que lhes falta é o direcionamento correto, é a oportunidade de refletirem sobre aquilo que vivenciam e aprendem todos os dias. Para finalizar este nosso debate em torno do que pôde ser observado a partir da proposta textual feita aos alunos trazemos aqui outros dois recortes:

Enunciado 9: "Quando ouvimos apenas a música acabamos criando imagens em nossa cabeça"

Enunciado 10: "[...] ao ler um livro começamos a imaginar a história em nossa mente"

A percepção dos estudantes vai além. Sem percebermos, a multimodalidade é parte íntegra da nossa concepção como seres falantes. No mundo moderno, somos bombardeados por todos os lados de informações, de textos, de significados. E esse aspecto de nossa relação com o mundo da comunicação não se detém apenas à realidade física, mas também ao mundo das ideias. Ao lermos um livro é impossível não representarmos, automaticamente em nossa mente, as imagens e situações relacionadas com a materialidade linguística. Em suma, o letramento multimodal precisa ser estudado, ser trabalhado em sala de aula, ser pensado por esse aluno do mundo contemporâneo. O letramento multimodal não deve ser considerado uma realidade discursiva estranha aos olhos da escola, do professor e do aluno. Para que isso ocorra, a questão multimodal precisa ser debatida, mas, antes de tudo, precisa ser colocada em prática.

É necessário que deixemos de lado nossos medos e rejeições em relação aos nossos estudantes, uma vez que, assim como foi comprovado com os resultados obtidos e analisados desta prática leitora, os estudantes têm sim noção de que vivem em um mundo de plurissignificação. $O$ que eles ainda não sabem é que precisam tornar-se indivíduos capazes de

Rev.Cad.Comun. Santa Maria, v.21, n.2, art 1, p.28 de 31, maio/ago.2017 
ler essas diversas significações para que, desse modo, possam inserir-se de forma ativa na sociedade da qual participam.

\section{CONSIDERAÇÕES FINAIS}

Este estudo comprometeu-se em analisar e trabalhar com textos multimodais em sala de aula, no intuito de proporcionar ao estudante não apenas o contato com esses textos, mas também instigar o pensar sobre as diferentes maneiras pelas quais determinados significados podem se desenhar. O principal objetivo proposto para este trabalho era procurar entender de que maneira o processo de compreensão textual multimodal é realizado pelos estudantes, para que dessa experiência possamos pensar em práticas mais eficazes de se trabalhar a multimodalidade.

Ao apresentar significações multimodais em sala de aula, pode-se perceber que os estudantes, assim como já desconfiávamos, não se sentem familiarizados com textos que não aqueles que a escola tradicional costuma trabalhar: textos não autênticos, preparados pura e simplesmente com intuito pedagógico, que muitas vezes não condizem com a realidade deste aluno e que não apresentam outras formas de significação que não sejam o código linguístico. Ao propormos análises imagéticas a partir da campanha publicitária e também do videoclipe, um primeiro desconforto dos estudantes em relação a esses textos foi bastante perceptível. Contudo, com o auxílio de questões norteadoras, como as apresentadas neste artigo, aos poucos a construção de significações multimodais por parte dos estudante foi se encaminhando e estes começaram a entender que, em um texto multimodal, toda e qualquer semiótica apresentada é passível de significação.

É interessante relatar que a campanha publicitária analisada em uma das oficinas foi o exemplo de texto multimodal que mais suscitou questionamentos nos estudantes. Tal campanha publicitária, como explicado durante a análise apresentada neste artigo, apresenta uma falha na concomitância de significados multimodais, já que a leitura imagética e a linguística são contraditórias. Porém, é preciso também levar em consideração a possibilidade de um sentido polissêmico no texto, já que podemos ter duas afirmações advindas deste texto: "baleia mas humano" e/ou "baleia e humano”. É nesse momento que cogitamos a noção de polissemia, que pode estar presente na campanha e que, portanto, não traria mais a

Rev.Cad.Comun. Santa Maria, v.21, n.2, art 1, p.29 de 31, maio/ago.2017 
ideia de contradição de que antes falávamos. A partir dessa experiência, surge uma sugestão que vem ao encontro do objetivo secundário desta pesquisa: pensar formas mais eficazes de se trabalhar a multimodalidade. Ao apresentarmos o insucesso de um texto multimodal, os estudantes perceberam como diferentes semióticas precisam estar em harmonia em um texto multimodal coeso. Dessa forma, fica a sugestão do trabalho não com textos multimodais nos quais as formas de significação se complementam e não há contradição, mas sim com textos que, de alguma forma, apresentam alguma falha e tornam mais visível para este estudante do que se trata a multimodalidade.

O desafio continua. Novas formas de ler e de ser no mundo se apresentam a cada instante que passa. A escola, como instituição de ensino, precisa acompanhar esse ritmo para que não perca a possibilidade de auxiliar esse estudante que vai para o mundo e que precisa de todas as subsídios necessários para se defender e se colocar nele. A multimodalidade também diz respeito a nós como indivíduos: não significamos apenas de uma maneira mas, antes disso, vivemos em um processo constante de metamorfose, na tentativa de nos situarmos nesse mundo de significações múltiplas.

\section{REFERÊNCIAS}

BAKHTIN, Mikhail. Estética da criação verbal. São Paulo: Martins Fontes, 2003.

BEYONCÉ. Pretty Hurts. Disponível em: < https://www.youtube.com/watch?v=LXXQLa$-5 n 5 \mathrm{~W}>$. Acesso em: 15 set. 2016.

CAMPANHA PUBLICITÁRIA. Grife de moda Reserva. A Gambiarra. Disponível em: https://www.agambiarra.com/reserva-faca-como-os-animais-nao-julgue/. Acesso em: 15 set. 2016.

FIORIN, José Luiz. Introdução ao pensamento de Bakhtin. São Paulo: Ática, 2008.

MARCUSCHI, Luiz Antônio. Produção textual, análise de gêneros e compreensão. São Paulo: Parábola Editorial, 2008.

ROJO, Roxane (org.). Escola conectada: os multiletramentos e as TICs. São Paulo: Parábola, 2013. 

bola, 2015 .

Hipermodernidade, multiletramentos e gêneros discursivos. São Paulo: Pará-

SOARES, Magda. Alfabetização e letramento. São Paulo: Contexto, 2004.

\section{Briane Schmitt}

Graduanda do oitavo nível de letras da Universidade de Passo Fundo - RS; e bolsista (CNPQ) do projeto de pesquisa intitulado Estudos enunciativos na atividade de trabaIho: cenografia e ethos em discursos socioprofissionais, coordenado pelo Prof. Dr. Ernani Cesar Freitas. E-mail para contato: brianeletras@gmail.com

\section{Ernani Cesar Freitas}

Doutor em Letras (PUCRS), com pós-doutorado em Linguística Aplicada e Estudos da Linguagem (PUCSP). Professor permanente do PPGL/UPF - RS. E-mail para contato: ecesar@upf.br

\section{Iverton Gessé Ribeiro Gonçalves}

Doutorando em Letras e bolsista institucional no Programa de Pós-graduação em Letras da Universidade de Passo Fundo - RS. Mestrado em Letras pela Universidade de Passo Fundo (2015). Possui graduação em Licenciatura Plena em Letras pela Universidade de Caxias do Sul (2011). E-mail para contato: hywertthom@hotmail.com

RECEBIDO EM: 01/12/2016

ACEITO EM: 01/02/2016 